\title{
Examination of a Benchmark for Ethical Care Competence in Basic Nursing Education
}

\author{
Emi Yoshioka*, Sayuri Kaneko \\ Nagano College of Nursing, Komagane City, Japan \\ Email: *eyoshioka@nagano-nurs.ac.jp, kanekosa@nagano-nurs.ac.jp
}

How to cite this paper: Yoshioka, E. and Kaneko, S. (2020) Examination of a Benchmark for Ethical Care Competence in Basic Nursing Education. Open Journal of Nursing, 10, 636-645.

https://doi.org/10.4236/ojn.2020.106044

Received: May 11, 2020

Accepted: June 12, 2020

Published: June 15, 2020

Copyright $\odot 2020$ by author(s) and Scientific Research Publishing Inc. This work is licensed under the Creative Commons Attribution International License (CC BY 4.0).

http://creativecommons.org/licenses/by/4.0/

\begin{abstract}
Objectives: With rapid advancements in medical care, nurses are confronted with ethical issues on a daily basis. If new nurses are introduced to the clinical setting without having acquired sufficient ethical judgment skills in basic nursing education, they are unable to respond to the ethical dilemmas they face. This results in learned helplessness, which can lead to burnout and turnover. Therefore, it is imperative to develop educational programs where there is a natural progression from basic to continuing nursing. Therefore, in this study, we conducted a nationwide survey using the Nursing Student Care Ethical Competence Scale to present a benchmark for the assessment of this skill and facilitate continuity in nursing education. Methods: From February to March 2019, we conducted a questionnaire survey of 4930 final-year nursing students enrolled in nursing colleges, junior colleges, and technical schools nationwide. The survey consisted of 29 items on ethical behavior, 26 items on ethics knowledge, and seven items on personal attributes. For the analysis, we calculated percentiles for the five standards of nursing students' ethical care competence: safe care provision, respecting self-determination, protecting personal information, providing the best care, and upholding patients' dignity. Results: Responses were obtained from 1505 nursing students (collection rate $30.5 \%$, valid response rate $30.5 \%$ ). The 80th percentile (minimum value-maximum value) was 128 (38 - 145) points for the ethical competence of nursing students, 37 (11 - 40) points for safe care provision, 28 (4 31) points for respect for self-determination, $23(5-25)$ points for protection of personal information, 23 (5 - 25) points for best care provision, and 13 (3 15) points for respect for personal dignity. Discussion: The 80th percentile was established as the benchmark for ethical care competence. Conclusion: Based on these criteria, nursing students can objectively assess their ethical behavior, allowing them to understand their strengths and weaknesses, articulate their challenges, and learn autonomously.
\end{abstract}

\section{Keywords}

Nursing Student, Ethical Care Competence 


\section{Introduction}

With advancements in medical care and the development of comprehensive community care systems, there has been an inevitable increase in the complexity of medical situations. Therefore, nurses are required to deal with ethical issues every day. In fact, with the constant diversification of ethical issues, nurses have many opportunities to work with professionals from other occupations, each of whom is required to make decisions based on their discipline and act in accordance with their professional code of ethics [1].

In the context of ethics, "Basic Nursing Practice Core Abilities and Achievement at Graduation" presents five core competencies [2]. In this group of skills, "Ability to defend the dignity and rights of people to be nursing" and "Ability to explain the necessary nursing care and obtain consent" regarding continuing nursing education for new nurses, as per the "Nursing Staff Training Guidelines," it is imperative to defend the human rights of patients, act based on ethics, obtain consent, and ensure confidentiality and privacy [3]. Furthermore, according to the Japan Nursing Association [4], it is necessary to develop a clinical ladder to establish indicators of nursing practice skills that are common to all nurses, and demonstrate the actual as well as desired positions of individual nurses with regard to practical skills [4].

From the above, although the necessity of emphasis on nursing ethics in both basic and continuing education has been suggested, the abstraction of ethical ability expected at each stage is high, and the specific educational contents and methods are different for each educational institution. And nursing ethics education is from the basic nursing education to the continuing nursing education. Beginning work in the clinical setting without having acquired the necessary ethical competence can deter new nurses from being able to respond to the ethical issues encountered daily, leading to a feeling of learned helplessness, which can, in turn, lead to burnout and turnover intention [5]. For this reason, education for acquiring ethical competence plays a major role in basic nursing education. Yoshioka et al. [6] pointed out that basic nursing education and ladder I, II, $\mathrm{IV}$, and $\mathrm{V}$ were not conducted as a result of an overview of basic nursing education and nursing ethics education for each ladder. There is a need to formulate educational programs where there is a natural progression from basic to continuing nursing; however, the development of such continuity is an issue. In order to solve this problem, it is necessary to present a benchmark of ethical competence at the time of basic nursing education graduation and to systematize continuous nursing ethics education based on visualized standards.

\subsection{Purpose}

The purpose of this study was to present a benchmark for ethical care competence in nursing students at graduation on the basis of a nationwide survey using the Nursing Student Care Ethical Competence Scale. In addition, we sought to make suggestions for the establishment of continuity in ethics education from 
basic to continuing nursing education.

\subsection{Definitions of Terms}

\subsubsection{Basic Nursing Education}

Basic nursing education is education prior to obtaining a public health nurse, midwife, or nurse license at an institution recognized by the Ministry of Education, Culture, Sports, Science and Technology or the Ministry of Health, Labour and Welfare [7].

\subsubsection{Continuing Nursing Education}

Continuing nursing education is an endeavor that supports learning to promote the improvement of knowledge, skills, and attitudes necessary to provide the best care after obtaining a nursing license [4].

\subsubsection{Clinical Ladder}

As per the definition provided by the Japan Nursing Association, the clinical ladder [8] is a stage-wise depiction of nurses' actual and expected practical ability. It is defined as a system whose ability is shown. Stage I corresponds to nurses with less than one year of experience, Stage II to nurses with one to less than three years of experience, Stage III to nurses with three to less than five years of experience, Stage IV to nurses with five to less than 10 years of experience, and Stage $\mathrm{V}$ to nurses with 10 or more years of experience.

\subsubsection{Ethical Competence}

In this study, ethical competence includes behavioral processes including thinking processes (ethical sensitivity, ethical reasoning, ethical decision-making) and nursing practice and introspection to solve ethical problems [9].

\subsubsection{Benchmark}

"Benchmark" refers to a reference point used in surveying. In this study, we used ethical competence as a numerical index.

\section{Methods}

\subsection{Sample}

We approached 803 of the nursing colleges, junior colleges, and vocational schools nationwide and sought participation from their final-year students. Among them, 4,930 final-year nursing students enrolled in eight nursing colleges, three junior colleges, and 98 vocational schools were ultimately surveyed.

\subsection{Survey Period and Data Collection}

An anonymous questionnaire survey was conducted from February to March 2019. The data collection method was approved in writing by the deans of the concerned institutions, and the number of respondents was confirmed by the person in charge. We checked with the staff of universities, junior colleges, and vocational schools for the target number of people. Next, the questionnaire was 
mailed to the person in charge, who then requested distribution to the persons being surveyed. After receiving the questionnaire, the survey respondents filled out a questionnaire, and after filling in the questionnaire, they were collected by post.

\subsection{Investigation}

\subsubsection{Personal Attributes}

Personal attributes included four items: age, gender, educational institution, and professional experience.

\subsubsection{Nursing Student Care Ethical Competence Scale (Table 1)}

In order to present a benchmark for nursing students' ethical care competence, we used the Nursing Student Care Ethical Competence Scale [10]. This tool, the reliability and validity of which have been established, is composed of 29 items across five factors. These five factors are "providing safe care," "respecting self-determination," "protecting personal information," "providing the best possible care," and "respecting individual dignity." Each item is evaluated on a five-point scale: 5 = fairly applicable, $4=$ somewhat applicable, $3=$ somewhat applicable, $2=$ not very applicable, and $1=$ not applicable at all. The higher the total score, the higher the ethical competence.

\subsection{Data Analysis}

Of the collected questionnaires, those in which the consent confirmation column was left unchecked and those where at least $80 \%$ of the items were incomplete were considered invalid responses. SPSS version 24 was used for all statistical analyses. The statistical significance level was $\mathrm{p}<0.05$.

\subsubsection{Personal Attributes}

Descriptive statistics were calculated for age, gender, educational institution, and work experience.

\subsubsection{Benchmark for Ethical Competence}

For the Nursing Student Care Ethical Competence Scale, we calculated a total score for all 29 items and individual scores for each of the five factors. Mean and standard deviation; minimum-maximum; 60th, 70th, 80th, 90th, and 100th percentiles; and the achievement rate (Score of each percentile/Total score of each factor) were calculated.

\subsection{Ethical Considerations}

This survey was conducted in an anonymous manner, and consent was determined by checking the consent confirmation column in the form. Participation was voluntary, and respondents were assured that refusal, or even abandoning the questionnaire midway, would do not affect their academic performance evaluation. Participants were informed that their data would remain confidential and only be used for research purposes. The study was conducted with the 
Table 1. Nursing student care ethical competence scale.

\begin{tabular}{l}
\hline Providing safe care \\
\hline 1 I collected information to understand situations where nurses physically restrain patients who are at risk of falling and \\
who fall while trying to move. \\
2 I considered the nurse's discomfort in restraining a patient at risk of falling and who falls while trying to move. \\
3 I considered the action to be taken for the protection of a patient who falls or is at risk of falling when trying to move on his own. \\
4 I decided upon the action to be taken after understanding why a patient at risk of falling when trying to move on their own \\
5 I manted to move. \\
6 In nursing practice, I was able to find my own ways to keep patients safe. \\
7 I thought about the causes of the patient's safety, whether or not, through nursing. \\
8 I rearranged the hurt feelings that the nurse felt as a result of restraining patients who are at risk of falling and who fall when \\
they try to move on their own.
\end{tabular}

Respecting self-determination

9 I collected information to understand situations where nurses do not ensure patients' privacy while providing care.

10 I collected information to understand situations where nurses fail to provide patients with the necessary explanations.

11 I thought about the cause of discomfort. When I saw a nurse giving care to a patient without privacy.

12 I thought about the cause of discomfort. When you see a nurse giving care to a patient without giving an explanation.

13 I thought there was a disadvantage. Nurses providing care to patients without giving explanations means that their self-determination is not being followed.

14 I considered ways to act to maintain the patient's right to self-determination.

15 In nursing practice, I was able to find my own ways to respect patients' right to self-determination.

16 I rearranged my feelings. I felt the discomfort I felt when patients were providing care without giving them privacy.

\section{Protecting personal information}

17 I collected information to understand situations where the conversations between nurses and patients about the latter's personal information were heard by other patients in the ward.

18 I considered the patient's discomfort when their personal conversations with nurses were heard by other patients.

19 I wondered about the protection, as well as lack of protection, of personal information.

I rearranged my unpleasant feelings. Nurses talking to patients about their personal information in the hospital room were heard by patients around them.

21 In nursing practice, I was able to find my own ways to protect patients' personal information.

\begin{tabular}{ll}
\hline 22 & Providing the best possible care \\
\hline 23 & I wondered about how to implement equal care for patients. \\
24 & I considered the causes both when I was able to practice equal nursing for patients and when I was not. \\
25 & I was able to find my own ways to practice equal nursing for patients. \\
26 & I rearranged the nervousness I felt when I saw a nurse making discriminatory remarks to a patient. \\
\hline 27 & I wespecting individual dignity \\
28 & I thought human dignity was not upheld when a nurse called a patient other than a pediatric patient "chan." \\
29 & I rearranged my unpleasant feelings. The feeling that I felt when the nurse called patients other than pediatric patients "chan."
\end{tabular}


approval of the Nagano Nursing University Ethics Committee (approval number 2018-20).

\section{Results}

\subsection{Participant Attributes}

Of the 4930 respondents surveyed, 1505 submitted completed questionnaires (recovery rate: $30.5 \%$ ). The number of valid responses was 1505 (valid response rate $100 \%)$. The average age of the participants was 22.7 years, and $1342(89.3 \%)$ were females. The number of university, junior college, and vocational school students was 157 (10.4\%), 20 (1.4\%), and $1328(88.2 \%)$, respectively. The number of nursing students with professional experience was 409 (27.6\%). Table 2 presents the descriptive statistics of participant characteristics.

\subsection{Descriptive Statistics and Achievement Rate of Ethical Competence (Table 2)}

Table 2 presents the descriptive statistics and achievement rates of nursing students' ethical care competence. The 100th percentile values of the five factors and the corresponding achievement rates were as follows: safe care provision: 40 points $(100 \%)$, respect for self-determination: 31 points $(77.5 \%)$, protection of personal information: 25 points (100\%), provision of the best care: 25 points (100\%), and respect for individual dignity: 15 points (100\%).

Table 2. Descriptive statistics and achievement rates of nursing student care ethical competence.

\begin{tabular}{|c|c|c|c|c|c|c|c|}
\hline \multicolumn{2}{|c|}{ Nursing Student Care Ethical Competence Scale } & \multirow{2}{*}{$\begin{array}{l}\text { Providing } \\
\text { safe care }\end{array}$} & \multirow{2}{*}{$\begin{array}{c}\text { Respecting } \\
\text { self-determination }\end{array}$} & \multirow{2}{*}{$\begin{array}{l}\text { Protecting } \\
\text { personal } \\
\text { information }\end{array}$} & \multirow{2}{*}{$\begin{array}{l}\text { Providing } \\
\text { the best } \\
\text { possible care }\end{array}$} & \multirow{2}{*}{$\begin{array}{c}\text { Respecting } \\
\text { individual } \\
\text { dignity }\end{array}$} & \multirow{2}{*}{ Total } \\
\hline Factor & & & & & & & \\
\hline Number of items & & 8 & 8 & 5 & 5 & 3 & 29 \\
\hline Score range & & $(8-40)$ & $(8-40)$ & $(5-25)$ & $(5-25)$ & $(3-15)$ & $(29-145)$ \\
\hline Average & & 32 & 23 & 18 & 19 & 9 & 111 \\
\hline Median & & 32 & 24 & 24 & 20 & 10 & 113 \\
\hline Minimum & & 11 & 8 & 5 & 5 & 3 & 38 \\
\hline Maximum & & 40 & 31 & 25 & 25 & 15 & 145 \\
\hline \multirow{2}{*}{ 60th percentile value } & Score & 34 & 24 & 20 & 20 & 11 & 116 \\
\hline & Achievement (\%) & $85.0 \%$ & $60.0 \%$ & $80.0 \%$ & $80.0 \%$ & $73.3 \%$ & $80.0 \%$ \\
\hline \multirow{2}{*}{ 70th percentile value } & Score & 35 & 26 & 21 & 22 & 12 & 121 \\
\hline & Achievement (\%) & $87.5 \%$ & $65.0 \%$ & $84.0 \%$ & $88.0 \%$ & $80.0 \%$ & $83.4 \%$ \\
\hline \multirow{2}{*}{ 80th percentile value } & Score & 37 & 28 & 23 & 23 & 13 & 128 \\
\hline & Achievement (\%) & $92.5 \%$ & $70.0 \%$ & $92.0 \%$ & $92.0 \%$ & $86.7 \%$ & $88.3 \%$ \\
\hline \multirow{2}{*}{ 90th percentile value } & Score & 39 & 30 & 25 & 25 & 15 & 136 \\
\hline & Achievement (\%) & $97.5 \%$ & $75.0 \%$ & $100 \%$ & $100 \%$ & $100 \%$ & $93.8 \%$ \\
\hline \multirow{2}{*}{ 100th percentile value } & Score & 40 & 31 & 25 & 25 & 15 & 145 \\
\hline & Achievement (\%) & $100 \%$ & $77.5 \%$ & $100 \%$ & $100 \%$ & $100 \%$ & $100 \%$ \\
\hline
\end{tabular}

The achievement rate (Score of each percentile/Total score of each factor). 
The 80th percentile and its attainment rates were as follows: safe care provision: 37 points $(92.5 \%)$, respect for self-determination: 28 points $(70.0 \%)$, protection of personal information: 23 points (92.0\%), provision of the best care: 23 points $(92.0 \%)$, and respect for individual dignity: 13 points (86.7\%).

The 60th percentile and its achievement rates were as follows: safe care provision: 34 points $(85.0 \%)$, respect for self-determination: 24 points $(60.0 \%)$, protection of personal information: 20 points $(80.0 \%)$, provision of the best care: 20 points $(80.0 \%)$, and respect for individual dignity: 11 points (73.3\%).

\section{Discussion}

\subsection{Survey Target}

The participants were 177 (11.8\%) nursing students enrolled in nursing colleges and junior colleges, and 1328 (88.2\%) nursing students enrolled in vocational schools. Of the 182,572 nursing students nationwide in 2017, the total capacity of full-time vocational schools and nursing colleges was 87,008 (48.0\%) and 90,364 (49.0\%), respectively [11], which differed slightly from the ratio of the number of educational institutions in this survey. However, participant characteristics, such as age, gender, and professional experience, were almost the same across the different institution types. Thus, the data in this study are considered reflective of the current scenario.

\subsection{Benchmark for Ethical Care Competence}

When we considered the achievement rates of the 60th, 70th, 80th, 90th, and 100th percentile values of nursing students' ethical competence, we found that among the five factors, only "respect for self-determination" tended to have a low achievement rate. There are two possible reasons for this. One is that students have few opportunities for direct communication owing to globalization and developments in IT. Many students feel that they are not good at communicating with patients [12]. Therefore, they have difficulty communicating with patients with dementia, bedridden patients, and children, and at the same time, find it hard to provide explanations that patients can easily comprehend. I think that having an influence on the respect for self-determination. The two points are that the hospitalized patients live in a hospital with limited medical care. If the patient's intentions cannot be respected because of medical limitations, the nurse will provide the patient with necessary information such as illness and restrictions due to treatment, consult with the patient if there is any ingenuity, and ask the patient for care. It is necessary to encourage self-determination [13]. However, for nursing students to ensure patients' self-determination of care, it is necessary to create an environment where they can easily express their intentions, and to work with other healthcare and welfare personnel [14]. It is thought that the difficulty involved in coordinating with nurses and healthcare and welfare stakeholders and nursing students' independent involvement affect respect for self-determination. 
If true, students desire $100 \%$ ethical competence. However, the "Nurses' Code of Ethics" points out that nursing students have difficulty connecting to ethical competence even if they possess the necessary theoretical knowledge. Therefore, the "Ethical Competence Scale of Nursing Student Edition Care" can acquire $100 \%$ of ethical competence from basic nursing education, even from the features covering Articles 1 to 6 of the "Nurses' Code of Ethics." I thought it would be difficult.

Therefore, considering the above, the benchmarks for ethical care competence at the time of basic nursing education graduation were $92.5 \%$ for safe care provision, $70.0 \%$ for respecting self-determination, and $92.0 \%$ for protecting personal information. We thought that setting the 80th percentile value of providing the best care (92.0\%) and respecting the dignity of the individual (86.7\%) was a reasonable criterion without deviation from reality.

\subsection{Possibility of Use of the Benchmark for Ethical Competence of Nursing Students}

The benchmark for ethical care competence of nursing students was the 80th percentile. The 80th percentile scores and their achievement rates were: safe care provision: 37 points (92.5\%), respect for self-determination: 28 points $(70.0 \%)$, protection of personal information: 23 points $(92.0 \%)$, provision of the best care: 23 points (92.0\%), and respect for individual dignity: 13 points (86.7\%). Using this benchmark, nursing students can compare their achievements with those of others nationwide, understand their own strengths and weaknesses, and educate teachers and teachers. By communicating self-tasks to others, it becomes possible to autonomously learn to acquire ethical competence while receiving support from others.

In continuing nursing education, the ethical competencies with low achievement rates, as identified in this study, can be focused on so as to adequately educate new nurses.

\subsection{Limitations and Future Prospects}

There are two possible limitations to this study. The first is the recovery rate. We conducted a large-scale survey at multiple facilities, but the recovery rate was just $30.5 \%$. This could have been owing to the survey period-February to March 2019-which coincided with the National Examination for Nurses and graduation ceremonies. Second, benchmarks can change with curriculum revisions in basic nursing education and the environment surrounding medical care; therefore, regular reviews are necessary.

In this study, we presented the benchmark for ethical care competence at the time of basic nursing education graduation. This benchmark can be interpreted as a goal to be achieved in basic nursing education as well as a starting point for continuing education. In the future, it is necessary to provide benchmarks for nurses to ensure continuity from basic to continuing education. 


\section{Conclusion}

The benchmark for nursing students' ethical care competence was set at the 80th percentile. The total score (achievement) for the 80th percentile was 128 points (88\%), and the scores for the individual competencies were as follows: 37 points (92.5\%) for safe care provision, 28 points $(70.0 \%)$ for respect for self-determination, 23 points $(92.0 \%)$ for protection of personal information, 23 points $(92.0 \%)$ for provision of the best care, and 13 points $(86.7 \%)$ for respect for individual dignity. Using this benchmark for ethical care competence, nursing students can compare their achievements with those of their counterparts nationwide, understand their own strengths and weaknesses, and educate teachers and teachers. By communicating self-tasks to others, it becomes possible to autonomously learn to acquire ethical competence while receiving support from others. In addition, teachers will be able to design lessons utilizing specific knowledge and learning support content to enhance the quality of students' ethical competence.

\section{Acknowledgements}

A portion of this paper was presented at the 38th conference of the Japan Academy of Nursing Science. The authors declare that they have no competing interests.

\section{Conflicts of Interest}

The authors declare no conflicts of interest regarding the publication of this paper.

\section{References}

[1] Ooue, Y., Kobayashi, Y., Nishiyama, T., et al. (2016) Changes in Nursing College Students Who Felt Themselves in "Basic Nursing Practice II" Changes in On-the-Job Training for Patients for the First Time (2nd Report). Hyogo University Review, 21, 49-58.

[2] Ministry of Education, Culture, Sports, Science and Technology (2011) Nursing Practice Skills and Goals at Graduation, Which Are the Core of Undergraduate Programs.

http://www.mext.go.jp/b_menu/shingi/chousa/koutou/47/siryo/_icsFiles/afieldfile/ 2011/11/04/1312488_5.pdf

[3] Ministry of Health, Labour and Welfare (2014) Newcomer Nursing Staff Training Guidelines.

https://www.mhlw.go.jp/file/06-Seisakujouhou-10800000-Iseikyoku/0000049466_1. pdf

[4] Japan Nursing Association (2012) Continuing Education Standards ver.2. https://www.nurse.or.jp/nursing/education/keizoku/pdf/keizoku-ver2.pdf

[5] Epstein, E.G. and Hamric, A.B. (2009) Moral Distress, Moral Residue, and the Crescendo Effect. Journal of Clinical Ethics, 20, 330-342.

[6] Yoshioka, E. and Kaneko, S. (2019) The Acquisition of Ethical Competence in Basic Education and the Present State of Ethics Education. Open Journal of Nursing, 9 , 676-686. https://doi.org/10.4236/ojn.2019.97052 
[7] Ministry of Health, Labour and Welfare (2007) Report of the Study Group on Enhancement of Basic Nursing Education.

https://www.mhlw.go.jp/shingi/2007/04/dl/s0420-13.pdf

[8] Japan Nursing Association (2016) Guide for Using "Nurse's Clinical Ladder (Japan Nursing Association Version)".

https://www.nurse.or.jp/nursing/education/jissen/pdf/tebiki.pdf

[9] Yoshioka, E. and Kaneko, S. (2019) The Current Status of Ethical Judgment Capacity and Ethical Training Regarding Continuous Nursing Education. International Journal of Nursing \& Clinical Practices, 6, 305. https://doi.org/10.15344/2394-4978/2019/305

[10] Yoshioka, E. and Kaneko, S. (2020) Development of the Care Ethical Competence Scale for Nursing Students. Japan Journal of Nursing, In Press.

[11] Japan Nursing Association (2017) Nursing Statistical Data. https://www.nurse.or.jp/home/statistics/index.html

[12] Nakayama, A. and Sawada, Y. (2013) A Study on Nursing Student Communication Exercises in Mental Nursing Support Theory. Bulletin of Niimi Public University, 34, 75-78.

[13] Ishii, T., Emori, Y. and Kawaguchi, T. (2014) Investigate and Practice the Essence of Nursing Ethics. 2nd Edition, Gakken Medical Shujunsha, Tokyo.

[14] Japan Nursing Association (2003) Nurse Code of Ethics. https://www.nurse.or.jp/home/publication/pdf/rinri/code_of_ethics.pdf 